\title{
COORDINATION BETWEEN SECTORS IN SHARED AIRSPACE OPERATIONS
}

\author{
Bonny Parke, Eric Chevalley, Paul Lee, Faisal Omar, Joshua M. Kraut, Kari Gonter, Abhay Borade, \\ Conrad Gabriel, Nancy Bienert, Cindy Lin, Hyo-Sang Yoo, San Jose State University Research \\ Foundation/NASA Ames, Moffett Field, CA \\ Everett Palmer, NASA Ames Research Center, Moffett Field, CA
}

\begin{abstract}
Recent studies have shown that a more efficient use of airspace may involve shared airspace operations, i.e., temporal as well as spatial separation of arrival and departure flows [1][2]. Temporal separation would permit a departure aircraft to fly through an arrival flow, depending on an available gap. This would necessitate careful and precise coordination between controllers in different sectors. Three methods of coordination which permit the penetration of a controller's airspace by another controller's aircraft are described: point out, lookand-go, and prearranged coordination procedure. Requirements of each method are given, along with associated problems that have surfaced in the field as described by Aviation Safety and Reporting System (ASRS) and other reports. A Human-in-the-Loop simulation was designed to compare two of the methods: point out and prearranged coordination procedures. In prearranged coordination procedures (P-ACP), the controllers control an aircraft in another controller's airspace according to specified prearranged procedures, without coordinating each individual aircraft with another controller, as is done with point outs. In the simulation, three experienced controllers rotated through two arrival sectors and a non-involved arrival sector of a Terminal Radar Approach Control (TRACON) airspace.
\end{abstract}

Results of eighteen one-hour simulation runs (nine in each of the two conditions) showed no impact of the coordination method on separation violations nor on arrival times for 208 departing aircraft crossing an arrival stream. Participant assessment indicated that although both coordination conditions were acceptable, the prearranged coordination procedure condition was slightly safer, more efficient, timely, and overall, worked better operationally. Problems arose in the point out condition regarding controllers noticing acceptance of point outs. Also, in about half of the point-out runs, time pressure was felt to have had an impact on when and if the departures could cross an arrival stream. An additional problem with point outs may be confusion in the field about which controller has responsibility for separating point-out aircraft from other aircraft.

\section{Background}

\section{Shared Airspace Operations}

Currently most aircraft are spatially separated in the National Air Space (NAS). A more efficient use of airspace may involve shared or "hybrid" spacing, which consists of both spatial and temporal spacing. Operationally, this type of spacing can involve sending a departure aircraft through a gap in an arrival flow on a more direct route to its destination. This results in the departure aircraft traversing an arrival sector's airspace, which requires careful coordination between controllers.

\section{Coordination Procedures}

In general, each controller has a delegated airspace, or sector, in the NAS. Within this airspace, the controller has full responsibility for the positioning of aircraft and for maintaining minimum separation standards. However, it has sometimes been more efficient for a controller from a different sector to have this responsibility, i.e., to control an aircraft in another controller's airspace. For example, if an aircraft is going through the corner of another controller's airspace, it doesn't make sense to make a hand-off and transfer radio communication to the controller who owns that airspace for the brief time that the aircraft will be in that airspace. The 
following three methods have evolved to deal with these and similar situations: point outs, look-and-go, and prearranged coordination procedure. Each will be discussed in the following sections.

\section{Point-Outs}

\section{FAA Point-out Requirements}

The FAA defines Point-outs as "A physical or automated action taken by a controller to transfer the radar identification of an aircraft to another controller if the aircraft will or may enter the airspace or protected airspace of another controller and radio communications will not be transferred." Point-out Approved is "The term used to inform the controller initiating a point out that the aircraft is identified and that approval is granted for the aircraft to enter the receiving controller's airspace, as coordinated, without a communications transfer or the appropriate automated system response" [3, p. 241]. Specific requirements as listed in the FAA Air Traffic Operations Policy 7110.65 (4/3/14) are as follows.

"a. The transferring controller must:

1. Obtain verbal approval before permitting an aircraft to enter the receiving controller's delegated airspace. [In the terminal], automated approval may be utilized in lieu of verbal, provided the appropriate automation software is operational (automated point out function), and the procedures are specified in a facility directive/LOA.

2. Obtain the receiving controller's approval before making any changes to an aircraft's flight path, altitude, speed, or data block information after the point out has been approved.

3. Comply with restrictions issued by the receiving controller unless otherwise coordinated.

4. Be responsible for subsequent radar handoffs and communications transfer, including flight data revisions and coordination, unless otherwise agreed to by the receiving controller or as specified in a LOA.

\section{b. The receiving controller must:}

1. Ensure that the target position corresponds with the position given by the transferring controller or that there is an association between a computer data block and the target being transferred prior to approving a point out.

2. Be responsible for separation between point out aircraft and other aircraft for which he/she has separation responsibility.

3. Issue restrictions necessary to provide separation from other aircraft within his/her area of jurisdiction" [3, pp. 244-5].

The FAA further stipulates that "When receiving a handoff, point-out, or traffic restrictions, respond to the transferring controller as follows: Radar Contact, Point-out Approved, or Traffic Observed, or Unable" [3, p. 242]. Also,

"When using the term 'traffic' for coordinating separation, the controller issuing traffic must issue appropriate restrictions. The controller accepting the restrictions must be responsible to ensure that approved separation is maintained between the involved aircraft" [3, p. 242].

An ideal automated point out interchange in the terminal that involves traffic therefore replicates the following verbal exchange (the automated procedure is in parentheses):

Controller A:

"Can I take aircraft through your airspace?" (Controller A flashes data tag of aircraft into B's airspace-it shows up flashing yellow on B's scope.)

Controller B:

"I have traffic you'll have to watch out for." (B flashes relevant traffic. It shows up flashing yellow on A's scope.)

Controller A:

"I see that and accept responsibility for avoiding it." (A accepts point out of relevant aircraft. It stops flashing but remains yellow.)

Controller B:

"Okay, point out approved." (B accepts original point out. It stops flashing but remains yellow.)

If Controller B does not flash the relevant traffic, it is assumed that Controller B will separate that traffic from A's point out aircraft. It can be seen that if there is traffic, this is a lengthy and timeconsuming process, and that if not completed 
correctly, it may lead to uncertainty as to which controller is in charge of separation in Controller B's airspace.

\section{Problems with Point Outs in the Field}

As reported in the Aviation Safety Reporting System, difficulties have been experienced in the field with the following aspects of point outs: designing point out procedures that take into consideration airspace complexity and controller workload, training, and tool support.

A problem with designing adequate point out procedures considering controller workload is described below.

"[Controller X] failed to point out . . . to the departure sector. I noticed the LJ60 climbing into my traffic; I immediately issued a turn to 180 heading on my F900. . . I have no idea the proximity, but it looked close. . . The X Sector is required to do the point out but that sector is very often extremely busy running all departures and arrivals for both $\mathrm{Y}$ airport and $\mathrm{Z}$ airport. So as it often happens, $\mathrm{X}$ is responsible for separation of 2 aircraft when he is talking to neither one. I understand it was an error on the $\mathrm{X}$ controller but it seems we could maybe standardize the procedure as it is done differently by numerous controllers" [4].

A problem with airspace design and training is described below.

"I don't know how to discourage the . . . lack of point outs. Perhaps [we should] take a similar situation in a video replay format and make it mandatory training? . . . O Our airspace, as you can see from. .. the ... map, has a lot of cutouts and different altitudes for each section. While it is impossible to eliminate all the cutouts, it should be a goal with future . . . redesign projects to simplify the airspace" [5].

Other ASRS reports on training illustrate the confusion about who has responsibility for separating point out aircraft from other traffic.

"Recommendation: X facility continues to show disregard for the meaning of Point Out. Suggest $\mathrm{X}$ facility gets regular training for Point Outs. It appears that they interpret Point Outs as permission to enter the $\mathrm{Y}$ facility's airspace, but are unaware that they are responsible for separation of affected aircraft" [6].

It should be noted that the above recommendation conflicts with the requirements on who is responsible for separating point out traffic from other traffic as specified by the FAA on the previous page. According to those requirements, it is the receiving controller who is "responsible for separation between point out aircraft and other aircraft for which he/she has separation responsibility." This is the case unless the receiving facility has pointed out any conflicting traffic to the requestor before accepting the point out.

Lack of tool support has sometimes caused problems with automated point outs. In one ASRS report, a controller made an amendment to an aircraft that had been pointed out, and was currently in another controller's sector, which caused the datablock to fall off the scope of the controller who had accepted the point out. The suggested fixes were modification of equipment or procedures, i.e., requiring coordination of route amendments between facilities [7].

In reviewing problems with point outs in the field, Ralph Grayson noted in 1981 that

"most of the point-out reports were similar . . . Acceptance of a point-out meant that relevant traffic was observed but not under coordinated control and, in many instances, its intentions were unknown. In situations where coordination is needed, the point-out technique can work reliably only where there is a framework of facility directives that defines coordinated operations utilizing point-outs." [8, p. 39]

\section{Look-and-Go}

Although this is not an FAA-approved procedure, it has been used in US airspace [8]. In this procedure, "a controller quick-looks the airspace being controlled by another, and if he observes no traffic pertinent to his plan, he clears the aircraft he is controlling into the adjacent airspace" [8, p. 40].

\section{Problems with Look-and-Go in the Field}

A loss of separation between an Airbus A320 and a Boeing 737-200 was described in a 1999 Canadian investigation report where a look-and-go procedure was operative in the Calgary Terminal Control Unit (TCU) [9]. Although there was a 
procedure for spatially separating arrival and departing aircraft, "the controllers favoured a process referred to as 'look and go'," which was seen as more efficient in maintaining traffic flow. According to the report,

"The Operations Letter describes 'look and go' as a process used to reduce or eliminate coordination whereby traffic under control of other positions is assessed and further action is taken with respect to that traffic."

The authors of the report note that

"This procedure requires that the controller continuously monitor traffic because the separation between departing and arriving aircraft may be vertical or lateral."

According to the report, the departure controller's responsibilities of keeping departing aircraft clear of the arrival controller's aircraft, "although implied in Operations Letter No. 98/20, are not explicit." This ambiguity contributed to the loss of separation [9]. Several other near misses as well as accidents have resulted from "the lack of redundancy that exists when the look-and-go concept is in use instead of full scale coordination" [8]. In sum, "visual coordination [is] an inadequate form of coordination. . .In reality, no coordination [takes] place" [8, p. 41]. Hence there is a need to have many more details about coordination procedures than is possible in the look-and-go procedure, which leads to the next section, Pre-arranged Coordination Procedures, or P-ACP.

\section{Pre-Arranged Coordination Procedure (P- ACP)}

\section{FAA Requirements}

The FAA describes prearranged coordination as "A facility's standardized procedure that describes the process by which one controller may allow an aircraft to penetrate or transit another controller's airspace in a way that assures standard separation without individual coordination for each aircraft" [3, p. 566].

More detailed specifications are:

"a. Air traffic managers at radar facilities must determine whether or not a clear operational benefit will result by establishing prearranged coordination procedures $(\mathrm{P}-\mathrm{ACP})$. Such procedures would allow aircraft under one controller's jurisdiction to penetrate or transit another controller's airspace in a manner that assures standard separation without individual coordination for each aircraft. When reviewing existing $\mathrm{P}-\mathrm{ACPs}$, or contemplating the establishment of these procedures, consideration must be given to airspace realignment to preclude coordination/penetration of another operational position's airspace. Prior to implementing a $\mathrm{P}-\mathrm{ACP}$, negotiations should be accomplished locally and all affected personnel must be thoroughly trained in the application of the procedures.

b. When $\mathrm{P}-\mathrm{ACP}$ are established, a facility directive must be published. The directive must include, as a minimum:

1. Requirement that the NAS Stage A (en route) or ATTS (terminal) systems are fully operational.

2. Procedures to be applied in the event that prearranged coordination procedures are not practicable.

3. The position(s) authorized to penetrate the protected airspace of an adjacent position.

4. Detailed responsibilities relating to $\mathrm{P}-\mathrm{ACP}$ for each position.

5. The requirement that two positions of operation cannot be authorized to penetrate each other's airspace simultaneously.

6. Controllers who penetrate another controller's airspace using $\mathrm{P}-\mathrm{ACP}$ must display data block information of that controller's aircraft which must contain, at a minimum, the position symbol and altitude information.

7. Controllers who penetrate another controller's airspace using $\mathrm{P}-\mathrm{ACP}$ must determine whether the lead aircraft is a heavy or B757 when separating aircraft operating directly behind, or directly behind and less than 1,000 feet.

8. Procedures to be applied for those modes of operation when the computer fails or is shut down, the beacon fails and only primary is available, and for non-beacon aircraft or at automated facilities aircraft without an associated full data block" [10, p. 105] . 


\section{Southern California TRACON (SCT) Example of P-ACP}

An example of an area where prearranged coordination takes place is in the vicinity of the Los Angeles Airport. Within this area, coordination is tightly prescribed between the following SCT sectors: Manhattan and Malibu and Manhattan and Laker.

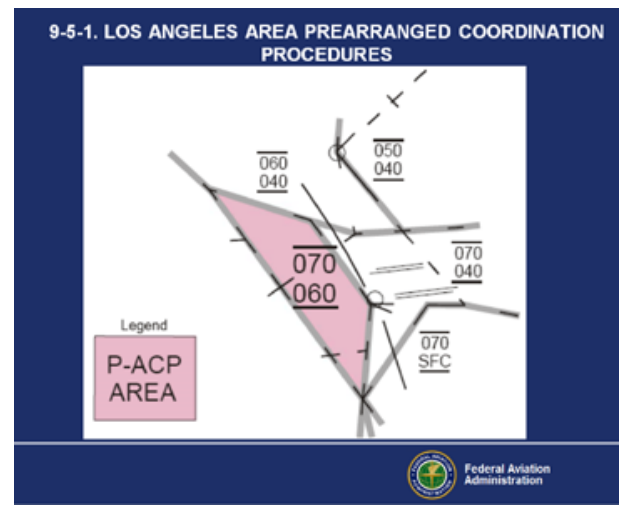

Figure 1.

For example, when LAX is in the West configuration, "(1) The Manhattan controller may apply P-ACP within the depicted boundaries of Laker airspace [shown in Figure 1 above]. (2) Prior to using P-ACP, the Manhattan and Laker controllers shall Quick Look each other or ensure Full Data Blocks are auto displayed to both sectors within P-ACP airspace. (3) Manhattan may enter P-ACP airspace with aircraft that depart Los Angeles International Runways 25L/R, or 24L/R. (4) The Manhattan controller shall be responsible for maintaining approved separation between aircraft under their control and all traffic in the P-ACP airspace" [11].

\section{Problems with P-ACP in the Field}

ASRS reports indicate that difficulties have been experienced in the field with the following aspects of P-ACPs: design, training, tool support, and workload. A problem with designing adequate PACPs is illustrated by the following ASRS report.

"The new prearranged coordination procedures [at my facility] are incorrect, flawed, and not safe. There are no restrictions with regards to altitudes, headings, or separation responsibility. There are no "right of way" rules defined in the prearranged coordination and the separation responsibility is unknown. . . This type of prearranged coordination is essentially a sanctioned form of "look and go," "run and gun," "turn and burn." . . . The "prearranged coordination procedures" at X need to be rewritten by someone who has knowledge and experience of prearranged coordination procedures" [12]. follows:

A problem with training P-ACPs is described as

"Once again our facility misapplied prearranged coordination procedures, except this time it lead to a loss of separation. . . I had previously filed a report on the misuse of prearranged coordination procedures and a loss of separation between two Air Carrier jets, one climbing and the other descending. This is a common occurrence here at $\mathrm{X}$ and there has been no refresher training provided. It is basically jungle rules at times. There is plenty of airspace for the Departure controllers to climb within their own airspace, above or below the arrivals descending via the STARs. We are having more and more of these types of close calls with no improvement. Specialists are not taught to remain in their airspace and misapply prearranged coordination procedures all the time. . . I recommend that prearranged coordination procedures. . .be suspended/terminated and the controllers [be] required to make a point out or stay in their own airspace" [13].

A problem with tool support of P-ACPs is described below. The auto-displays in STARS were not working and yet,

". . . The auto displays are required in the $\mathrm{X}$ 7110.65 for prearranged coordination climbs in designated areas. Without this function people are still climbing but do not realize, or are forgetting that these aircraft are not properly displayed to the appropriate positions, and thus the Controller should not be using prearranged coordination areas" [14].

Finally, even with good design, training, and tool support, there are those that say P-ACP increases workload. "I still remain certain that there is an increased workload placed upon the RADAR Approach/Departure Controller, all over the interpretation of 'Pre-arranged Coordination'" [15]. 


\section{Unanswered Questions On Shared Airspace Operations and Coordination Procedures}

Given the fact that shared airspace operations require precise coordination between controllers, the question is, "Which type of coordination-point outs or prearranged coordination, is safest, most efficient, and does not require undue workload by either controller in shared airspace operations?" Our goal was to answer this question by testing these two types of coordination in a simulation involving shared airspace operations. Each type of coordination would adhere to FAA guidelines and have clear and explicit rules.

\section{Method}

\section{Simulated Airspace}

The simulated airspace was in the Northern California TRACON (NCT), and was focused on the Loupe departures from San Jose Airport (SJC), as shown in Figure 1 below. Instead of all of the Loupe departures making the high altitude loop eastward to fly above the arrival streams as is currently the case, some aircraft flew on a departure that was newly created for the simulation-the Reddt3 departure. This departure gave the controller two options: flying the aircraft under 5,000 feet below the arrivals (the safe route), or flying through the arrival streams when a sufficient gap was available. The three arrival streams were the Panoche arrival into Oakland (OAK), the Modesto arrival into San Francisco (SFO), and the Madwin arrival into OAK, as shown in Figure 2.

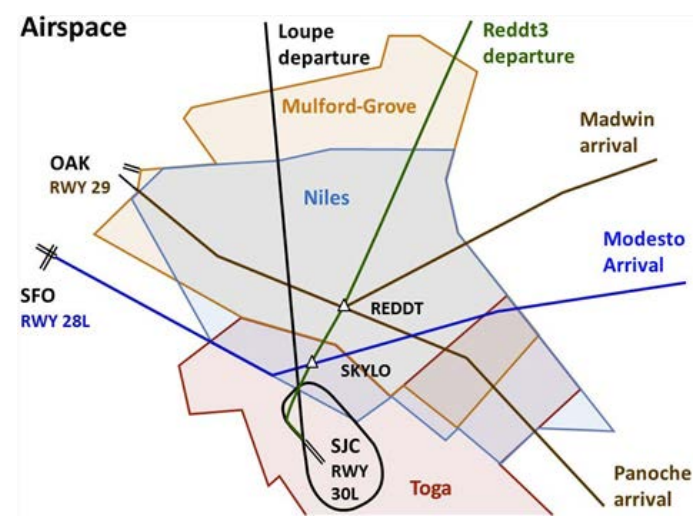

Figure 2. Simulation Airspace

\section{Experimental Design}

The experiment was a test not only of coordination types, but of support tools to help controllers decide whether to climb a departure below or through arrival streams. (The description and results of the different tool sets can be found in an accompanying paper presented at this conference [16].) The experiment consisted of 18 one-hour runs, with 4-5 runs per day over 4 full days. The data collection days were preceded by a day of training and practice runs. As shown in Figure 3, the experiment was a $2 \times 3 \times 3$ factorial design with two coordination types and three tools tested in three different traffic scenarios. Traffic in the scenarios was based on actual traffic. The aircraft call signs in each of the scenarios were changed each time the scenario was presented.

\begin{tabular}{|c|c|c|c|}
\hline Run \# & Coordination & Tool Set \# & Scenario \# \\
\hline 1 & Pointout & 1 & 3 \\
\hline 2 & Pointout & 2 & 2 \\
\hline 3 & Pointout & 3 & 1 \\
\hline 4 & PACP & 1 & 3 \\
\hline 5 & PACP & 2 & 1 \\
\hline 6 & PACP & 3 & 2 \\
\hline 7 & Pointout & 2 & 1 \\
\hline 8 & Pointout & 1 & 2 \\
\hline 9 & Pointout & 3 & 3 \\
\hline 10 & PACP & 2 & 2 \\
\hline 11 & PACP & 1 & 1 \\
\hline 12 & PACP & 3 & 3 \\
\hline 13 & Pointout & 3 & 2 \\
\hline 14 & Pointout & 2 & 3 \\
\hline 15 & Pointout & 1 & 1 \\
\hline 16 & PACP & 2 & 3 \\
\hline 17 & PACP & 3 & 1 \\
\hline 18 & PACP & 1 & 2 \\
\hline
\end{tabular}

Figure 3. Experimental Design

\section{Participants}

Three highly experienced controllers rotated through the following arrival positions:

1. Mulford, who made the decision to fly below or through the arrival streams with the Reddt3 departures,

2. Niles, who controlled the Modesto arrivals, and

3. Sunol, who transferred control for the Panoche and Madwin arrivals to 
Mulford and who handed off the Modesto arrivals to Niles.

The participants were retired controllers who had controlled traffic for an average of 26 years, 14 years of which were in a TRACON. The average time from retirement was 4.6 years. ${ }^{1}$

\section{Coordination}

A previous simulation showed that having an arrival sector control the Reddt3 departures first instead of a departure sector reduced the overall coordination needed [17]. Early control of the aircraft gave the arrival controller more time to make a decision on whether to climb the aircraft and improved departure climb performance.

\section{Point outs}

The point out coordination for Mulford and Niles, two arrival sectors, was as follows. Mulford had control of the Reddt3 departures on contact after they departed SJC. These aircraft needed to go through Toga's departure airspace (and possibly Niles' airspace, if the decision were made to climb them early). Reddt3 departure's datablocks were therefore automatically displayed to the Toga departure sector. Mulford needed to point out each Reddt3 departure to Niles (even though the departure could have stayed in Mulford's airspace below 5,000 '). Reddt 3 departures needed to stay on the Reddt3 departure route. With point out approval from Niles, Mulford could climb Reddt3 departures up to 11,000 ' through Niles' airspace. Niles also pointed out relevant traffic on the Modesto arrival to Mulford.

\section{Prearranged Coordination}

As in the point out condition, Mulford had control of the Reddt3 departures on contact after departing SJC, and again, Reddt3 departure

${ }^{1}$ Five other retired controllers participated in supportive positions, some of whom were testing other tools. SJC Tower released Reddt3 aircraft to Mulford, Toga Departure handled the SJC Loupe and other departures, Ghost Final received hand-offs from Niles and Mulford, Richmond Departure received Mulford's Reddt3 hand-offs, and Ghost High, a center controller, received hand-offs from Richmond. datablocks were shown to Toga. In the prearranged coordination condition, however, Mulford had automatic control for climbing through Niles airspace. In this condition, it was clearly specified that Mulford needed to ensure separation of Reddt3 departures from all traffic in Niles' airspace. Reddt3 departure datablocks were automatically displayed to Niles and datablocks of Modesto arrivals between 4,000' and 11,000' in Niles' airspace were automatically displayed to Mulford.

\section{Apparatus}

Standard Terminal Automation Replacement System (STARS) displays, including automated point out capability, were emulated within Multi Aircraft Control System (MACS) software [18], and shown on large-format monitors similar to those used in current air traffic control facilities. MACS provides a high fidelity environment to simulate traffic, test tools and procedures, and collect data. In addition, the controllers were able to contact other sectors by radio communication.

\section{Workload and Participant Feedback}

During the simulation runs, the controllers were prompted every three minutes to report their current workload on a scale of 1 to 6 using Workload Assessment Keypads (WAKs). Ratings of 1 and 2 were considered to be low workload, ratings of 3 and 4 were considered to be medium workload, and ratings of 5 and 6 were considered to be high workload.

After each run, the controllers responded to an online post-run survey, and after the simulation, they responded to a post-sim survey and participated in a debrief. Survey questions included those on workload, acceptability, feasibility and safety of the operations and coordination. The questions were typically binary (yes/no), or involved ratings on a 5point Likert scale, ranging from 1 (lowest) to 5 (highest). Space was made available for comments on both survey instruments. WAK and post-run data were analyzed with repeated measures Analyses of Variance (ANOVAs). 


\section{Results}

\section{Experimental Results}

There were no differences in separation violations nor in arrival times at destination points between the two coordination conditions.

\section{Participant Assessments}

\section{Workload and Acceptability of Workload}

Overall, there were some indications that the controllers' workload was lower in the P-ACP condition than in the point out condition.

The WAK workload ratings which took place every three minutes were low but there were no differences in mean ratings between the two coordination conditions (1.7 each) for the Mulford and Niles positions.

However, a post-run measure of workload showed a slightly higher mean rating for the point out condition that fell just short of significance. This was in response to the question "In the last run, how much mental activity was required during the busiest time?" The ratings from the participant controllers were on a five-point scale ranging from "Very low mental activity" to "Very high mental activity." As shown in Figure 4, the participants' average rating of their mental activity during the busiest time was low to moderate, but slightly higher in the point out condition $(M=2.5)$ than in the P-ACP condition ( $M$ $=2.3$ ). However, this reached significance only at the $p=.07$ level, $(M S=.02, F(1,2)=12$, SEs adjusted per Loftus \& Masson [19] and Morey [20], error bars $=95 \%$ CIs.

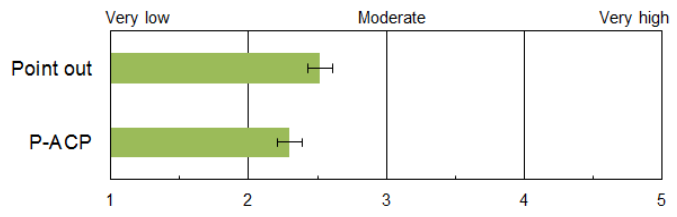

Figure 4. Mental Activity

In the post run survey, there was no difference in the coordination conditions on the acceptability of workload, which was rated as a 5 (very acceptable) on a 1-5 scale on all runs by the three controllers.
In the post sim survey, however, although all of the controllers rated the workload as very acceptable in the P-ACP condition, (a 5 on a 1-5 scale), only two of the three did so in the point out condition. One controller rated the workload in the point out condition as only "Somewhat acceptable,"-a 3 on a 1-5 scale.

\section{Efficiency}

As shown in Figure 5, in the post-run survey, controllers in the Mulford and Niles positions rated the runs in the P-ACP condition as having more efficient coordination than the point out condition. The ratings were in response to the question "In this run, how efficient was the coordination procedure for the Reddt3 departures?" (Ms $=3.9 \& 5.0, M S=9.4$, $F(1,15)=19.0, p<.01$, error bars $=95 \%$ CIs. $)$

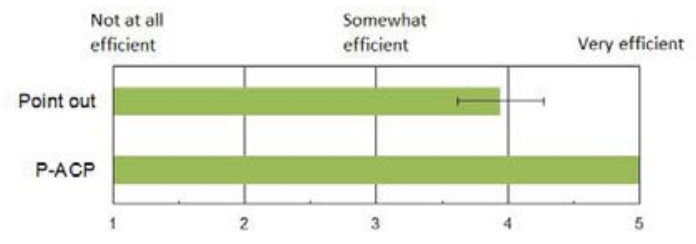

Figure 5. Efficiency of Coordination

As shown in Figure 6, in the post-run survey, the controllers in the Mulford and Niles positions rated the runs in the P-ACP condition as having more timely coordination than the point out condition. The ratings were in response to the question "All in all, in this run was the coordination accomplished in a timely fashion?" ( $M s=4.2 \&$ 5.0, $M S=2.6, F(1,14)$ $=8.2, p<.01$, error bars $=95 \%$ CIs.)

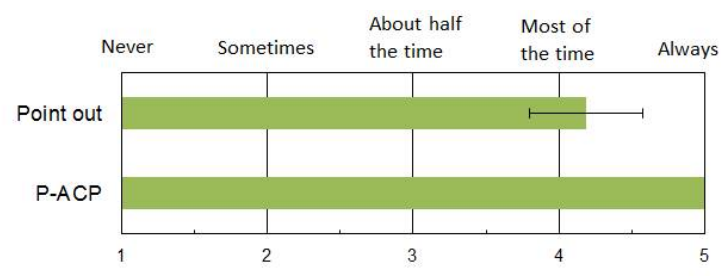

Figure 6. Timeliness of Coordination

Finally, in response to the post-sim survey question, "Which type of coordination do you think worked better operationally?", all three controllers indicated that the coordination in the P-ACP condition worked better operationally. Their average rating is depicted in Figure 7. 


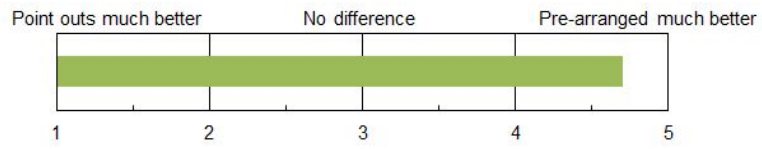

Figure 7. Operationally Worked Better

The participants made the following statements in support of their ratings: "Mulford can see the traffic and no sense coordinating when not necessary."

- $\quad$ "Pre-arranged helps more when traffic is very busy."

- $\quad$ "Regular point outs are more time-consuming and cumbersome. The pre-arranged is much cleaner."

\section{Safety}

After each run, controllers in the Mulford and Niles positions were asked, "In this run, how safe was the coordination procedure for the REDDT3 departures?" As shown in Figure 8, the controllers thought that both procedures were safe, but there were more runs, on average, where the controllers thought that point outs were less safe. $(M s=4.6 \&$ $5.0, M S=.68, F(1,16)=7.8, p<.01$, error bars $=95 \%$ CIs.)

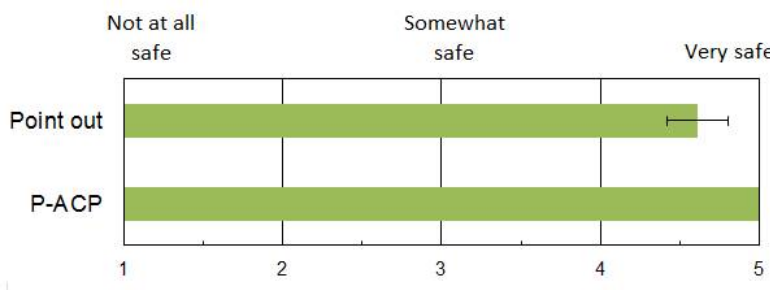

Figure 8. Safety of Coordination

Also, in the post-sim survey, although all controllers thought that coordination and safety were "Very acceptable" (5s on a 1-5 scale) in the prearranged coordination condition, only two did so for the point out condition; one controller thought that both safety and coordination in the point out condition were only "somewhat acceptable" (3 on a 1-5 scale).

When asked to compare the two conditions directly in terms of safety, there was a difference of opinion. One controller thought the P-ACP condition was much safer, stating "Making point outs and phone calls is distracting--could lead to errors."
Another thought that both conditions were equally safe, "They are both safe, just different." A third thought the point out condition was slightly safer, saying that point outs "force both controllers to answer the other's message."

Many safety features of the simulation worked well in each of the conditions, as revealed in the postsim survey.

In the prearranged coordination condition,

- $\quad$ Niles was sufficiently alerted to Reddt3 departures going through Niles' airspace (average rating of 5.0 on a 1-5 scale), and

- The full data blocks displayed to Mulford in Niles' airspace were sufficient to show Mulford any traffic (average rating of 5.0 on a 1-5 scale),

In the point out coordination condition,

- Niles was sufficiently alerted to Reddt 3 departures going through Niles' airspace (average rating of 5.0 on a $1-5$ scale)

- Niles found it easy to notice Mulford's point outs of Reddt3 departures (average rating of 4.7 on a $1-5$ scale), despite a flashing limited datablock.

\section{Problems with Point outs}

It was sometimes difficult for Mulford and Niles to notice when point outs were accepted. In the postrun survey, controllers in the Mulford and Niles position were asked, "In this run, how difficult was it for you to notice when your point outs were accepted by the other controller?" Mean responses for the nine point out runs are shown in Figure 9. Although the means are close to the middle of the scale, there were some runs with ratings of "Very difficult," or 5 on a 1-5 scale. A comment from a controller in the Mulford position was "Difficult to determine if Niles accepted my point out. I had to redo or call to verify" (Run 7). 


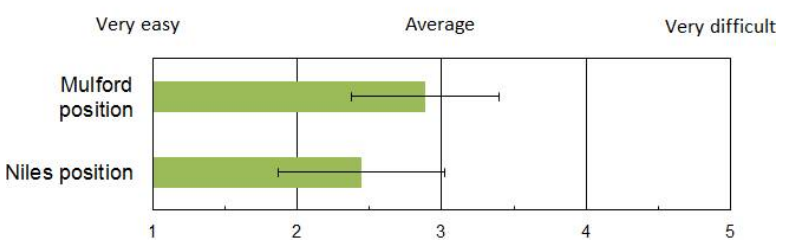

Figure 9. Noticing Point Out Acceptance

Mulford indicated that on average, over half the time Niles did not point out conflicting traffic, as shown in Figure 10 . In the post-run survey, controllers in the Mulford position were asked, "In this run, if there was traffic that conflicted with the Reddt3 departures, did Niles point out this traffic?"

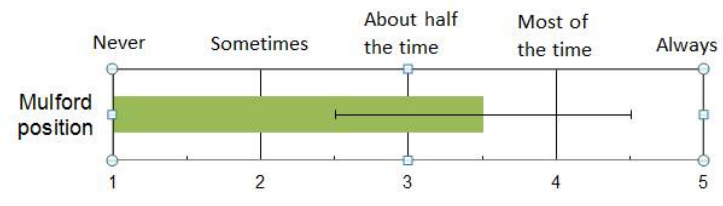

\section{Figure 10. Pointing Out Conflicting Traffic}

It is possible that Niles did not point out the conflicting traffic because he took responsibility for separating this traffic from the Reddt3 departures. However, in the post-sim survey, two of the controllers stated that there were times when Niles should have pointed out traffic to Mulford and did not. One of the controllers commented that this also happened in the field and better training would solve it.

Perhaps most important, there was time pressure on at least one point out coordination in about half the point out runs for both Mulford and Niles. In the post-run survey, the controllers were asked, "In the last run, was there time pressure on even a single one of these coordinations?" Controllers in each position specified that there was time pressure in four of the nine runs. The controller in the Mulford position was also asked, "If there was a delay in point out coordination, did it have an impact on the Reddt3 aircraft vertical profile or lateral route?" For half of the point out runs the answer was yes. ${ }^{2}$

${ }^{2}$ A factor further complicating the point out condition that occurred both in the simulation and occurs today in the field is that within a TRACON facility there is no way for a controller to make an automated point out on an aircraft that has already been handed off. In the field, after handing off to a different facility,

\section{Balancing Workload, Efficiency, and Safety}

A question that required the respondents to consider all elements of the two coordination procedures at once was the post-sim question: "If you were in charge of implementing shared airspace operations in the field, please indicate which method of coordination you would put in place: point outs or prearranged coordination procedures?" All opted for prearranged coordination procedures.

\section{Discussion}

It appears from the review of problems in the field that both coordination procedures would benefit from tightly prescribed rules that are rigorously followed and trained. Fortunately these requirements exist: the detailed requirements given in the FAA 7210.3Y [10] for implementing a P-ACP would ensure that this procedure would not resemble a "Look and Go" procedure. Especially important is the requirement that

"prior to implementing a $\mathrm{P}-\mathrm{ACP}$, negotiations should be accomplished locally and all affected personnel must be thoroughly trained in the application of the procedures."

Similarly, point out requirements are wellspecified in the 7110.65 [3] although there is evidence that point out coordination could be improved by a "framework of facility directives" specifying their precise meaning as suggested by Grayson [8]. The difficulty of executing point outs properly in high traffic suggests redesigning airspace to minimize point out coordination. It is important to improve training on who is responsible for separating approved point out aircraft from other traffic. Controller confusion on who has responsibility for separating the point out aircraft from other aircraft is a safety issue in and of itself.

this capability is in place. Therefore, according to a participant in the simulation, after handing off within a facility, a controller needs to

"revert to the old method of forcing the data tag onto the scope of the person [being shown the point out] and then calling them on the landline to make a verbal point out. . . Because [controllers] like the automation better than the verbal, many ... will not initiate a handoff until all of their point outs have been done with the automation. This often leads to handoffs getting made late and sometimes even forgotten and can contribute to someone falling behind when the traffic is busy." 
At the beginning of the study, it appeared that choosing between the two coordination methods depended on the importance of timeliness (favoring P-ACP) vs. having structured, individual, closedloop, and therefore perhaps safer coordination (favoring point outs).

Results from the simulation showed, however, that a well-designed and trained prearranged coordination procedure not only has the advantages of efficiency and timeliness, but was judged in the post-run surveys as being safer and appeared to have fewer problems overall. In the end, all of the participants said they would choose prearranged coordination procedures instead of point outs for implementing shared airspace operations in the field.

\section{Summary}

Recent studies have shown that a more efficient use of airspace may involve both spatial and temporal spacing of arrival and departure flows. This would involve a high degree of coordination between controllers. Three methods of coordination which involve the penetration of a controller's airspace by another controller's aircraft were described: point out, look-and-go, and prearranged coordination. Procedural requirements of each method were given, along with problems that have surfaced in the field as described by ASRS and other reports.

Two of the methods were compared in a simulation: point out and prearranged coordination procedure. Results of eighteen one-hour simulation runs (nine in each of the two conditions) showed no impact of the coordination method on separation violations and arrival times at destination points. Participant assessment indicated that although both coordination conditions were acceptable, the prearranged coordination procedure condition was seen as slightly safer, more efficient, timely, and overall as working better operationally. Problems arose in the point out condition regarding controllers noticing acceptance of point outs, as well as the time pressure that was felt to have had an impact on the Reddt3 departures in about half of the point-out runs. An additional problem with point outs may be controller confusion in the field about who has responsibility for separating point-out aircraft from other aircraft.

\section{References}

[1] Capozzi, Brian J, Stephen C. Atkins, Seongim Choi, 2009, Towards optimal routing and scheduling of metroplex operations, AIAA 20097037, Proceedings of the AIAA Aviation Technology, Integration, and Operations Conference.

[2] Xue, Min, Shannon Zelinski, 2012, Optimal integration of departures and arrivals in terminal airspace, AIAA 2012-4977, Minneapolis, Proceedings of the AIAA Guidance, Navigation, and Control Conference.

[3] FAA, 2014, Air Traffic Organization Policy, JO 7110.65. Retrieved on 8-25-14 from https://www.faa.gov/documentLibrary/media/Order/ ATC.pdf

[4] NASA, 2013, Aviation Safety Reporting System (ASRS), ACN \#1092292. Retrieved on 8-2414 from http://asrs.arc.nasa.gov/

[5] NASA, 2010, Aviation Safety Reporting System (ASRS), ACN \#890610. Retrieved on 8-2414 from http://asrs.arc.nasa.gov/

[6] NASA, 2010, Aviation Safety Reporting System (ASRS), ACN \#879749. Retrieved on 8-2414 from http://asrs.arc.nasa.gov/

[7] NASA, 2011, Aviation Safety Reporting System (ASRS), ACN \#963546. Retrieved on 8-2414 from http://asrs.arc.nasa.gov/

[8] Grayson, Ralph L., 1981, Information transfer in the surface component of the system: Coordination problems in air traffic control. In C.E. Billings \& E. S. Cheaney (Eds.) Information Transfer Problems in the Aviation System (pp. 25-45). Retrieved on 8-26-14 from http://ntrs.nasa.gov/archive/nasa/casi.ntrs.nasa.gov/19 810022620.pdf\#page $=29$

[9] Transportation Safety Board of Canada, 1999, Aviation Investigation Report \#A99W0064, retrieved on 5-13-14 from http://www.tsb.gc.ca/eng/rapportsreports/aviation/1999/a99w0064/a99w0064.pdf

[10] FAA, 2014, JO 7210.3Y, p. 105. Retrieved on 8-25-14 from http://www.faa.gov/documentlibrary/media/order/fac. pdf 
[11] FAA, 2005, Manhattan: Los Angeles Area. Powerpoint slide presentation for FAA students.

[12] NASA, 2010, Aviation Safety Reporting System (ASRS), ACN \#911507. Retrieved on 8-2414 from http://asrs.arc.nasa.gov/

[13] NASA, 2012, Aviation Safety Reporting System (ASRS), ACN \#1019673. Retrieved on 8-2414 from http://asrs.arc.nasa.gov/

[14] NASA, 2013, Aviation Safety Reporting System (ASRS), ACN \#1087387. Retrieved on 8-2414 from http://asrs.arc.nasa.gov/

[15] NASA, 2010, Aviation Safety Reporting System (ASRS), ACN \#875981. Retrieved on 8-2414 from http://asrs.arc.nasa.gov/

[16] Chevalley, Eric, et al., 2014, Decision support tools for climbing departure aircraft through arrival airspace, $33^{\text {rd }}$ Digital Avionics System Conference, Colorado Springs, Colorado.

[17] Chevalley, Eric, Bonny Parke, Paul Lee, Faisal Omar, Hwasoo Lee, Nancy Bienert, Joshua Kraut, Everett Palmer, 2013, Scheduling and separating departure aircraft crossing arrival flows in shared airspace, $33^{\text {rd }}$ Digital Avionics System Conference, Colorado Springs, Colorado.

[18] Prevot, Thomas, Paul Lee, Todd Callantine, Joey Mercer, Jeffrey Homola, Nancy Smith, and Everett Palmer, 2010, Human-in-the-loop evaluation of NextGen concepts in the Airspace Operations Laboratory, AIAA 2010-7609, Toronto, Proceedings of the AIAA Modeling and Simulation Technologies Conference.

[19] Loftus, Geoffrey R., Michael E. J. Masson, 1994. Using confidence intervals in within-subject designs, Psychonomic Bulletin \& Review, 1, 476-490.

[20] Morey, Richard D., 2008, Confidence intervals from normalized data: A correction to Cousineau (2005). Tutorial in Quantitative Methods for Psychology. 4(2), 61-64.

\section{Acknowledgments}

The authors would to thank the skilled air traffic controllers who participated in this study.

\section{Email Address}

bonny.parke@nasa.gov

33rd Digital Avionics Systems Conference

October 5-9, 2014 